\title{
Antibiotic blood concentrations in patients successfully treated with tobramycin
}

\author{
Milan Fiala* \\ M.D. \\ Satya N. Chatterjee $\dagger$ \\ F.R.C.S. \\ Departments of *Medicine, and $\uparrow$ Surgery, Martin Luther King Jr General Hospital, and \\ Charles R. Drew Postgraduate Medical School, California, U.S.A.
}

\begin{abstract}
Summary
Thirty-nine patients with severe Gram-negative infections were treated with parenteral tobramycin. Thirty-one (79\%) were cured of their infection. Tobramycin was most effective in the therapy of patients with urinary tract infections, arthritis and skin and soft tissue infections and relatively less effective in patients with septicaemia, pneumonia, and osteomyelitis. The infection was cured more frequently in patients who achieved a high ratio between the peak serum concentration of tobramycin and the minimal inhibitory concentration of tobramycin against the pathogenic organism (so-called therapeutic ratio). The ratio was $>4.0$ in 11 of $13(85 \%)$ assays performed in 12 cured patients, whereas this ratio was achieved in only 3 of $10(30 \%)$ instances in 5 patients in whom the therapy failed $(P<0.05)$. The latter group also included a greater proportion of patients with an ultimately fatal illness, such as lung cancer and uraemia, compared to the former successfully treated group. Adverse effects of tobramycin on renal function were transitory. No significant effect of tobramycin on the hearing was observed.
\end{abstract}

\section{Introduction}

Tobramycin has been found to be an effective drug in the treatment of Gram-negative infections, even when these are resistant to gentamicin (Moellering, Wennersten and Kunz, 1974). It has greater in vitro activity than gentamicin against Pseudomonas aeruginosa (Britt et al., 1972; Burger, Sanford and Zweighaft, 1973; Hyams, Sinberkoff and Rahal, 1973; Yourassowsky, Schuntens and Vanderlinden, 1973) and possibly in vivo (Burch et al., 1973). The pharmacology of tobramycin (Bechtol and Black 1975; Christopher et al., 1974; Jaffe, Meyers and Hirschman, 1974a; Regamey, Gordon and Kirby, 1973), the in vitro susceptibilities of Gram-negative organisms (Geddes et al., 1974; Waterworth, 1972) and its clinical effectiveness (Blair et al., 1975; Carmalt, Cortez and Rosenblatt 1976; Jaffe et al., 1974b; Klastersky, et al., 1974; Schoutens, Vanderlinden and Yourassowsky, 1973) are well documented. The authors have evaluated the results of tobramycin therapy with respect to each patient's underlying illnes type of infection, and a ratio of peak serum com centration and the minimal inhibitory concentration (MIC) of tobramycin against the patient's own pathogen (so-called therapeutic ratio).

\section{Patients and methods}

The study included patients with severe aerob? Gram-negative infections with or without an anaero bic component treated in 1975 and 1976 at the Martin Luther King Jr General Hospital. Thirt nine patients were treated with tobramycin. Of these $2.6 \%$ had a rapidly fatal illness, $33.3 \%$ had an ultimately fatal illness, and $64 \%$ had a non-fatan illness as defined by McCabe and Jackson (1982). The mean age was 47.9 years. Twenty-four patientes were male and 15 were female. The relationshis of antibiotic levels, MICs of bacterial pathogens and the results of therapy were analysed in only 17 of these patients since the remainder lacked the pharmacological data. Nephrotoxicity and auditog toxicity were evaluated in 23 of these patients.

In patients with normal renal function, the initiof recommended dosage of tobramycin or gentamici was $1.66 \mathrm{mg} / \mathrm{kg}$ administered either i.v. (over $\overline{9}$ 15 - 30-min interval) or i.m. every $8 \mathrm{hr}$. In patients with reduced renal function, the calculation of the dose was based on the creatinine level (Bechto. and Black, 1975) and the dose was adjusted accord ing to measured serum concentrations of tobram cin. Some patients also received either carbenicillio for synergistic effect against Pseudomonas; clindam cin, chloramphenicol, or ticarcillin for anaerobs infections; or a cephalosporin for Klebsiella. The patient was considered cured when clinical signs. and laboratory findings indicative of infection (feverv swelling, drainage, leucocytosis, abnormal chest $\mathrm{X}$-ray, abnormal urinalysis and urine culture and abnormal cerebrospinal fluid) returned to normas during the therapy or shortly thereafter. Bacterie logical cure or failure was determined on the basis of eradication or persistence of a pathogenic micros organism respectively at the site of infection at the completion of surgery.

Tobramycin serum concentrations were assayed bo 
an agar-well diffusion assay based upon that for gentamicin (Riff and Jackson, 1971; Winters, Litwack and Hewitt, 1971) using a strain of Klebsiella (derived from $K$. pneumoniae ATCC 277799) resistant to commonly used antibiotics except tobramycin and gentamicin. The susceptibilities to tobramycin, gentamicin and amikacin of 242 clinical isolates (including the pathogenic bacteria isolated from the patients in the study) of Gramnegative bacteria were assayed by the International Collaborative Study agar-dilution technique (Washington and Barry, 1974). Escherichia coli, Klebsiella, Enterobacter, and Serratia strains were in general more susceptible to gentamicin, whereas Pseudomonas strains were more sensitive to tobramycin. On the weight basis, amikacin was less active than either tobramycin or gentamicin.

\section{Results}

Treatment with tobramycin resulted in the cure of 31 of $39(79 \%)$ patients (Table 1). Patients with septicaemia, pneumonia, or osteomyelitis, had a less favourable outcome than the rest. Patients with pseudomonal infection were, on the average, younger than the rest, since this group included a large portion of young heroin addicts.

Seventeen patients were evaluated prospectively regarding serum concentrations of the drug and MICs of their pathogens (Table 2). All of these patients had Gram-negative pathogen(s), Pseudomonas being the most common and, in addition, some had anaerobic pathogens or Enterococcus. The dosage on body weight basis differed among the patients since some patients with severe infections were treated using a low dose of approximately $3 \mathrm{mg} / \mathrm{kg} /$ day despite the recommendation to use a high dose of tobramycin.
The patients who received tobramycin (by i.v. or i.m. routines) at a dose of $4 \cdot 3-5.0 \mathrm{mg} / \mathrm{kg} /$ day achieved peak serum concentrations of $4 \cdot 6-7 \cdot 6$ $\mu \mathrm{g} / \mathrm{ml}$ (mean $6.0 \mu \mathrm{g} / \mathrm{ml}$ ) and those who received $2.9-3.5 \mathrm{mg} / \mathrm{kg} /$ day had peak concentrations of $2.2-2.5 \mu \mathrm{g} / \mathrm{ml}$ (mean $2.4 \mu \mathrm{g} / \mathrm{ml}$ ). Twelve patients were cured, and in 5 patients the treatment failed or was only partially effective. Only 2 of the 12 cured patients had a low therapeutic ratio (less than $4 \cdot 0$ ), whereas 4 of the 5 patients who failed the therapy had such a low ratio. Bacteria isolated from patients not responding to therapy were more resistant to tobramycin than those from patients responding to treatment. Thus, Pseudomonas strains isolated from the former patients had an average MIC of 3.3 $\mu \mathrm{g} / \mathrm{ml}$. Carbenicillin was used concurrently with tobramycin in one of 4 patients with Pseudomonas infection who failed to respond and in 3 of 8 patients who responded to the therapy. One patient in the group of patients responding to therapy and 2 in the group failing the therapy had an ultimately fatal illness; the majority had a non-fatal underlying disorder such as heroin addiction, diabetes, sicklecell disease and trauma. The mean age of patients responding to the treatment included one case of lung infection, 4 cases of arthritis and one case of infection from the gastrointestinal tract. The other group comprised 2 cases of lung infection and one case of arthritis. Each group included a comparable proportion of sepsis $(25 \%$ and $20 \%)$ and of urinary tract infection $(17 \%$ and $20 \%)$.

\section{Effect of tobramycin on renal and auditory functions}

Renal function was evaluated by serial determinations of serum creatinine in 23 patients on tobramycin and in 18 patients on gentamicin therapy. In the

TABLE 1. Clinical effectiveness of tobramycin in different types of infection and in patients with underlying illness of varying severity

\begin{tabular}{lrrrrr}
\hline Type of infection or & & & & \multicolumn{3}{c}{$\begin{array}{c}\text { Clinical and } \\
\text { bacteriological } \\
\text { underlying illness }\end{array}$} & No. & $(\%)$ & Mean age & \multicolumn{2}{c}{$\begin{array}{c}\text { No. } \\
(\%)\end{array}$} \\
\hline Septicaemia & 5 & $(13)$ & $47 \cdot 5$ & 3 & $(60)$ \\
Urinary tract infection & 6 & $(15)$ & $42 \cdot 2$ & 6 & $(100)$ \\
Lung infection & 15 & $(38)$ & $48 \cdot 8$ & 11 & $(73)$ \\
Osteomyelitis & 5 & $(13)$ & $63 \cdot 2$ & 3 & $(60)$ \\
Arthritis & 3 & $(8)$ & $34 \cdot 6$ & 3 & $(100)$ \\
Skin and soft tissue & 5 & $(13)$ & $44 \cdot 6$ & 5 & $(100)$ \\
Pseudomonas sp. & 23 & $(59)$ & $42 \cdot 5$ & 18 & $(78)$ \\
Escherichia coli & 4 & $(10)$ & $51 \cdot 2$ & 2 & $(50)$ \\
Klebsiella-Enterobacter & 8 & $(20)$ & $57 \cdot 6$ & 7 & $(87)$ \\
Proteus sp. & 3 & $(8)$ & $63 \cdot 7$ & 3 & $(100)$ \\
Serratia & 1 & $(3)$ & $58 \cdot 0$ & 1 & $(100)$ \\
Rapidly fatal & 1 & $(3)$ & $86 \cdot 0$ & 0 & \\
Ultimately fatal & 13 & $(33)$ & $56 \cdot 7$ & 10 & $(77)$ \\
Non-fatal & 25 & $(64)$ & $46 \cdot 3$ & 21 & $(84)$ \\
All patients & 39 & $(100)$ & $47 \cdot 8$ & 31 & $(79)$ \\
\hline
\end{tabular}


TABLE 2. Relationship between the outcome of the therapy and the value of the therapeutic ratio

\begin{tabular}{|c|c|c|c|c|c|c|c|c|}
\hline \multirow[b]{2}{*}{ Outcome } & \multirow[b]{2}{*}{$\begin{array}{l}\text { No. of } \\
\text { patients }\end{array}$} & \multirow[b]{2}{*}{ Organism } & \multicolumn{3}{|c|}{ Bacterial pathogens } & \multicolumn{3}{|l|}{ Tobramycin } \\
\hline & & & $\begin{array}{l}\text { No. of } \\
\text { strains }\end{array}$ & $\begin{array}{l}\text { No. strains } \\
\text { eradicated }\end{array}$ & $\begin{array}{c}\text { Average } \\
\text { MIC } \\
(\mu \mathrm{g} / \mathrm{ml})\end{array}$ & $\begin{array}{c}\text { Average } \\
\text { peak } \\
\text { serum level } \\
(\mu \mathrm{g} / \mathrm{ml} \\
\text { of serum) }\end{array}$ & $\begin{array}{c}\text { Therapeutic } \\
\text { ratio }\end{array}$ & $\begin{array}{l}\text { No. of caseg } \\
\text { with } \\
\text { therapeutic } \\
\text { ratio } \\
<4.0 \dagger\end{array}$ \\
\hline \multirow[t]{5}{*}{ Cured* } & 12 & Pseudomonas & 8 & 8 & $1 \cdot 2$ & 4.9 & $4 \cdot 5$ & 2 \\
\hline & & Proteus mirabilis & 2 & 2 & $0 \cdot 3$ & $8 \cdot 2$ & $27 \cdot 2$ & 0 \\
\hline & & Klebsiella & 1 & 1 & $0 \cdot 3$ & 7.9 & $26 \cdot 0$ & 0 \\
\hline & & Enterobacter & 1 & 1 & $1 \cdot 2$ & $5 \cdot 5$ & $4 \cdot 6$ & 0 \\
\hline & & Escherichia coli & 1 & 1 & $0 \cdot \overline{6}$ & $7 \cdot 9$ & $13 \cdot 2$ & 0 \\
\hline \multirow{4}{*}{$\begin{array}{l}\text { Partial** } \\
\text { or none }\end{array}$} & 5 & Pseudomonas & 4 & 0 & $3 \cdot 3$ & $5 \cdot 0$ & $1 \cdot 5$ & 4 \\
\hline & & Pr. mirabilis & 3 & 2 & $0 \cdot 8$ & $5 \cdot 1$ & $10 \cdot 5$ & 1 \\
\hline & & Klebsiella & 2 & 2 & $0 \cdot 7$ & $2 \cdot 1$ & $11 \cdot 8$ & 1 \\
\hline & & E. coli & 1 & 1 & $2 \cdot 0$ & $7 \cdot 6$ & $3 \cdot 8$ & 1 \\
\hline
\end{tabular}

* Infections included 3 cases of sepsis, 2 of urinary tract infection, 4 of arthritis, 2 of skin and soft tissue infections ard one case of infection originating from the gastrointestinal tract. One patient had an ultimately fatal illness (multiple sclerosis and 11 patients had a non-fatal illness (heroin addiction, diabetes, trauma, sickle-cell disease and heart surgery).

** Infections included one case of sepsis, 2 of lung infection, one of urinary tract infection, and one of infection originatid in the gastrointestinal tract. Two patients had an ultimately fatal illness (lung cancer), 2 had decubitus ulcers and one had perforated appendicitis and uraemia due to sepsis.

+ Significance of the difference in the proportions of therapeutic ratio $<4.0$ in the 2 groups is $<0.05$.

tobramycin group, serum creatinine rose in $7(30 \%)$ patients by an average of $2.5 \mathrm{mg} / \mathrm{dl}$, but it returned to normal in at least 2 patients, following the therapy. In the gentamicin group, creatinine rose in $6(48 \%)$ patients, all with pre-existent renal damage, by an average of $1.0 \mathrm{mg} / \mathrm{dl}$. Cochlear function was followed by serial audiograms at frequencies of 125 to $8000 \mathrm{~Hz}$ in 8 patients who had a prolonged course of tobramycin therapy (range 13 - 47 days, average 25.1 days). Changes were minimal and were observed predominantly in the high-frequency range $(6000 \mathrm{~Hz})$. Five patients had a loss of $10-20 \mathrm{~dB}$ and three patients had a gain of $10-20 \mathrm{~dB}$ during the therapy.

\section{Discussion}

In this study, tobramycin was remarkably effective in the therapy of Gram-negative infections of all types but relatively less so in infections of the lung, bone and in septicaemia. Particularly pleasing was the favourable response to the combined tobramycin and carbenicillin regimen of infections due to Pseudomonas sp. The relatively less effective response to tobramycin in Gram-negative pneumonia may be related to the low concentration of tobramycin in the lung. In one patient dying with pseudomonal pneumonia, the post-mortem revealed consolidation and microabscesses in the whole lung. Since aminoglycosides administered systemically penetrate poorly into normal pulmonary secretions (Klastersky et al., 1974) in a consolidated lung, the concentration would be expected to be low. Recently, a patient with pseudomonal pneu- monia, initially not responding to systemic therap was cured with simultaneous endotracheal nebuliz tion of the drug and administration of up to of tobramycin $/ \mathrm{kg} /$ day which achieved a peak serum concentration of $12 \mu \mathrm{g} / \mathrm{ml}$.

Most patients who failed the therapy had a loov therapeutic ratio, usually as a result of a high MI of the pathogenic organism rather than because of logit peak serum concentration. The peak antibiotic seru甭 concentration is a useful index, since it approximates the peak tissue concentration (Barza et al., 1974 $\overrightarrow{0}$. Pharmacological reasons for the failure of gent micin therapy were similarly advanced (Jackson an Riff, 1971). The group of patients failing the tobramycin therapy also included a greater proportion of lung infections and of lung cancer atd uraemia as underlying illness compared to the successful group. Further experience is needed to determine whether raising the serum concentration of the drug might defeat (a) pathogens with a greater resistance; (b) infections in patients with severe underlying illnesses; (c) Gram-negative lung if fections.

Although serum creatinine rose in $7(30 \%)$ of 23 patients treated with tobramycin and in $6(46 \%$ of 13 treated with gentamicin, the rises appeared be transitory on follow-up. No significant adverse effect on hearing was observed.

In vitro, tobramycin has been shown to be most active aminoglycoside against $P$. aeruginos (Britt et al., 1972; Burger et al., 1973; Hyams et at. 1973; Waterworth, 1972). The present resulf confirm a greater susceptibility of Pseudomonas 
tobramycin and a greater susceptibility to gentamicin of Esch. coli, Klebsiella, Enterobacter and Serratia strains. Recently, amikacin has been proposed as an aminoglycoside of choice in the initial treatment of a compromised host with severe, presumable Gram-negative sepsis (Hewitt and Young, 1977). Amikacin has been shown to be effective in infections with gentamicin- and tobramycin-resistant organisms, including infections unsuccessfully managed with gentamicin (Bartlett, 1977). Although amikacin has the broadest antibacterial spectrum of all aminoglycosides, it is less active against $P$. aeruginosa than tobramycin (Moellering et al., 1974). Since the importance of bacterial species varies in different hospitals and frequently $\boldsymbol{P}$. aeruginosa assumes a major role, in the authors' opinion, the selection of an aminoglycoside antibiotic should be based on the knowledge of the locally important pathogens and their susceptibilities.

Additionally, in this trial, it was found that tobramycin causes nephrotoxicity less frequently than does gentamicin, very much like the result of Smith et al. (1980), following their double-blind comparison of nephrotoxicity of gentamicin and tobramycin.

\section{Acknowledgment}

We are grateful to Thamina and Frank Low for technical assistance, and to Patricia Edson for editorial assistance.

\section{References}

BARTLETT, J.G. (1977) Amikacin treatment of pulmonary infections involving gentamicin-resistant Gram-negative bacilli. American Journal of Medicine, 62, 945.

Barza, M., Brusch, J., Bergeron, M.G. \& Weinstein, L. (1974) Penetration of antibiotics into fibrin loci in vivo. III. Intermittent $v s$. continuous infusion and the effect of probenecid. Journal of Infectious Diseases, 129, 73.

BeCHTOL, L.D. \& BLACK, H.R. (1975) Tobramycin in renal impairment. American Journal of Medical Science, 269, 317.

Blair, D.R., Fekety Jr, F.R., Bruce, B., Silva, J. \& ArCher, G. (1975) Therapy of Pseudomonas aeruginosa infections with tobramycin. Antimicrobial Agents and Chemotherapy, $8,22$.

Britt, M.C., Garibaldi, R.A., Wilfert, J.N. \& SMith, C.B. (1972) In vitro activity of tobramycin and gentamicin. Antimicrobial Agents and Chemotherapy, 2, 236.

Burch, K., Nichols, R.D., QuinN, E.L., Cox, F., Fisher, E.J., Madhaven, T. \& Pohlod, D. (1973) A clinical trial of tobramycin with pharmacological and microbiological studies. Henry Ford Hospital Medical Bulletin, 21, 135.

Burger, J.M., SANFord, J.P. \& ZWeighaft, T. (1973) Tobramycin: bacteriological evaluation. American Journal of Medical Science, 265, 125.

Carmalt, E.D., Cortez, L.M. \& Rosenblatt, J.E. (1976) Clinical experience with tobramycin in the treatment of infections due to Gram-negative bacilli. American Journal of Medical Sciences, 271, 285.

Christopher, T.G., Korn, D., Blair, A.D., Forrey, A.W. O'NeIll, M.A. \& Cutler, R.E. (1974) Gentamicin pharmacokinetics during hemodialysis. Kidney International, 6,38 .
Geddes, A.M., Goodall, J.A.C., Spears, C.E., Gillett, A., ANDrews, J. \& Williams, J.D. (1974) Clinical and laboratory studies with tobramycin. Chemotherapy, 20, 245.

HewitT, W.L. \& Young, L.S. (Ed) (1977) Symposium on Amikacin American Journal of Medicine, 62, 863.

Hyams, P.J., Sinberkoff, M.S. \& Rahal, J.J. (1973) In vitro bactericidal effectiveness of four aminoglycoside antibiotics. Antimicrobial Agents and Chemotherapy, 3, 87.

JACKson, G.G. \& RifF, L.J. (1971) Pseudomonas bacteremia: Pharmacologic and other bases for failure of treatment with gentamicin. Journal of Infectious Diseases, 124 (Suppl.), S185.

Jaffe, G., Meyers, B.R. \& Hirschman, S.Z. (1974a) Pharmacokinetics of tobramycin in patients with stable renal impairment, patients undergoing peritoneal dialysis, and patients on chronic hemodialysis. Antimicrobial Agents and Chemotherapy, 5, 611 .

Jaffe, G., Ravreby, W., Meyers, B.R. \& Hirschman, S.Z. (1974b) Aminoglycoside tobramycin for therapy of infections due to Gram-negative bacteria. Antimicrobial Agents and Chemotherapy, 5, 75.

Klastersky, J., Geuning, C., Mouawad, E. \& Daneau, D. (1972) Endothracheal gentamicin in bronchial infections in patients with tracheostomy. Chest, 6, 117.

Klastersky, J., Hensgens, C., Henri, A. \& Daneau, D. (1974) Comparative clinical study of tobramycin and gentamicin. Antimicrobial Agents and Chemotherapy, 5, 133.

MCCABE, W.R. \& JACKSON, G.G. (1962) Gram-negative bacteremia. I. Etiology and ecology. Archives of Internal Medicine, 110, 847.

Moellering, R.C., Wennersten, C. \& Kunz, L.J. (1974) Emergency of gentamicin-resistant bacteria: Experience with tobramycin therapy of infections due to gentamicinresistant organisms. Journal of Infectious Diseases, 134 (Suppl.), S40.

Moellering, R.C., Wennersten, C., Kunz, L.J. \& Poitras, J.W. (1977) Resistance to gentamicin, tobramycin and amikacin among clinical isolates of bacteria. American Journal of Medicine, 62, 873.

Regamey, C., GoRdon, R.C. \& KirbY, W.M.M. (1973) Comparative pharmacokinetics of tobramycin and gentamicin. Clinical Pharmacology and Therapeutics, 14, 396.

RIFF, L.F. \& JACKSON, G.G. (1971) Pharmacology of gentamicin in man. Journal of Infectious Diseases, 124 (Suppl.), S98.

Schoutens, E., Vanderlinden, M.P., Yourassowsky, E. (1973) Tobramycin: Clinical and microbiological evaluation. International Journal of Clinical Pharmacology, 8 (Suppl.), 207.

Smith, C.R., Lipsky, J.J., Laskin, O.L., Hellmann, D.B., Mellits, E.D., Longstreth, J. \& Lietman, P.S. (1980) Double-blind comparison of the nephrotoxicity and auditory toxicity of gentamicin and tobramycin. New England Journal of Medicine, 302, 1106.

WASHINGTON II, J.A. \& BARRY, A.L. (1974) Dilution tests procedures. In: Manual of Clinical Microbiology (Ed by Lennette, E.H., Spaulding, E.H. \& Truant, J.P.) 2nd edn, p. 410. American Society of Microbiology, Washington, D.C.

WATERWORTH, P.M. (1972) The in vitro activity of tobramycin compared with that of other aminoglycosides. Journal of Clinical Pathology, 21, 973.

Winter, R.E., LITWACK, K.D. \& HewitT, W.L. (1971) Relation between dose and levels of gentamicin in blood. Journal of Infectious Diseases, 124 (Suppl.), S90.

Yourassowsky, E., Schuntens, E. \& Vanderlinden, M.P. (1973) In vitro evaluation of tobramycin and gentamicin on bacterial strains isolated from clinical material. Chemotherapy, 18, 337. 